\title{
MUKJIZAT NARATOLOGIS: Studi Andragogi atas Kisah Musa-Khidr dalam Surah Al-Kahfi 60-82
}

\author{
Nurul Azizeh \\ Universitas Nurul Jadid Probolinggo \\ azizehnurul@gmail.com
}

Diterima 14 Februari 2019 | Direview 27 Maret 2019 | Diterbitkan 27 Juni 2019

\begin{abstract}
:
This study wants to explore the story of Prophet Moses and Khidr as figures of adult education in the perspective of Islamic education. The main issue of this study is how the concept of adult education in the perspective of Islamic education is able to increase the spectrum space of andragogical education. By using content analysis and narrative approaches that are primarily sourced QS. al-Kabfi: 60-82, this study seeks to show the values of Islamic education that are based on the theory of andragogical education. The characterization of Moses and Khidr as a figure of andragogical education is: Moses is present as the subject of andragogical education which has a sense of curiosity and Khidr as an object, a figure who has ladunni knowledge and high spiritual abilities. Through the method of lecture, discussion and demonstration, Musa-Khidr's narrative dialogue shows adult learning that contains the values of Islamic education, namely the moral value between teacher and student and morality in learning. The implication of this paper is an effort to contribute to scientific repertoire in the world of education as one of the dimensions of the naratological miracles of the Qoran.
\end{abstract}

Keywords: Musa-Khidr Narrative, Andragogical Theory, Islamic Education.

\begin{abstract}
Abstrak:
Penelitian ini ingin mengeksplorasi kisah Nabi Musa dan Khidr sebagai tokoh pendidikan orang dewasa dalam perspektif pendidikan Islam. Masalah utama dari penelitian ini adalah bagaimana konsep pendidikan orang dewasa dalam perspektif pendidikan Islam mampu meningkatkan ruang spektrum pendidikan andragogi. Dengan menggunakan analisis konten dan pendekatan naratif yang terutama bersumber QS. al-Kahfi: 60-82, penelitian ini berupaya menunjukkan nilai-nilai pendidikan Islam yang didasarkan pada teori pendidikan andragogi. Karakterisasi Musa dan Khidr sebagai tokoh pendidikan andragogi adalah: Musa hadir sebagai subjek pendidikan andragogis yang memiliki rasa ingin tahu dan Khidr sebagai objek, sosok yang memiliki pengetahuan ladunni dan kemampuan spiritual yang tinggi. Melalui metode ceramah, diskusi dan demonstrasi, dialog narasi Musa-Khidr menunjukkan pembelajaran orang dewasa yang mengandung nilai-nilai pendidikan Islam, yaitu nilai moral antara guru dan siswa dan moralitas dalam pembelajaran. Implikasi dari makalah ini adalah upaya untuk berkontribusi pada repertoar ilmiah di dunia pendidikan sebagai salah satu dimensi dari keajaiban naratologis Alquran.
\end{abstract}

Kata Kunci: Musa-Khidr Narrative, Teori Andragogi, Pendidikan Islam.

\section{Pendahuluan}

Dalam beberapa dekade terakhir ini, pendidikan andragogi menjadi salah satu kajian yang semakin intens dibahas dalam dunia pendidikan. Melihat fakta yang mengherankan bahwa selama ini masih sedikit sekali pemikiran, investigasi maupun tulisan tentang andragogi dari segi kacamata pendidikan Islam. Walaupun kajian ini sudah menjadi concern umat manusia sejak abad ke-19. Meminjam pendapat Malcolm Knowles yang dikenal sebagai bapak andragogi mengungkapkan bahwa kurangnya riset terkait pendidikan orang dewasa sungguh mengherankan sebab menilai dari sejarah para guru besar di masa Yunani Kuno dan Romawi kuno kebanyakan adalah para guru bagi orang dewasa, bukan anak-anak. ${ }^{1}$ Dalam perkembangan pendidikan Islam pun masih jarang sekali membahas teori-teori pendidikan andragogi, terlebih lagi mengambil sumber data dari al-Quran.

Al-Quran sebagai salah satu mukjizat Nabi Muhammad yang paling agung dan terjaga keasliannya hingga hari ini. Tujuan dan misi utama al-Quran tidak lain sebagai kitab bidayah (petunjuk) bagi manusia. Selain berisi ajaran, perintah maupun larangan, kitab suci ini

${ }^{1}$ Malcolm Shepherd Knowles, The Adult Learner: The Definite Classic in Adult Education and Human Resource Development, (Houston: Gulf Publishing Company, 1998), h. 35. 
mengandung banyak cerita-cerita. Dalam al-Quran sendiri, terdapat surat al-Qashas yang berarti cerita-cerita sebagai isyarat pentingnya posisi dan peran cerita dalam al-Quran. ${ }^{2}$ Cerita seolah menjadi mediasi al-Quran untuk menyampaikan hidayah. Selain itu, al-Quran seakanakan menjadikan cerita sebagai salah satu bentuk dalam penyampaian tujuannya. Ini terbukti dengan adanya lebih dari seribu ayat dari 6666 ayat dalam al-Quran yang memuat tentang cerita-cerita, baik cerita para nabi maupun kaum-kaum terdahulu. ${ }^{3}$

Sebagai bagian dari diskursus al-Qur'ân, cerita Musa juga telah menjadi salah satu media yang banyak mewarnai dakwah Nabi Muhammad. Hal ini terbukti dengan pengulangan cerita tersebut dalam al-Quran penyebutan cerita Musa melebihi cerita para nabi yang lain. ${ }^{4}$ Sharif Mazari berpendapat bahwa model pengisahan seperti itu menjadi suatu kelebihan dari naratologi al-Qur'ân (al-sardiyah al-Qur'aniyah) yang berpijak pada prinsip dualisme (mabda' al-thuna'iyah). ${ }^{5}$

Kisah Musa sebagai salah satu kisah pendidikan yang paling banyak diceritakan dalam al-Qur'an, yaitu kurang lebih hadir dalam 30 surat dalam bentuk yang fragmentatif. Walaupun tidak dihadirkan secara utuh, mulai awal sampai akhir, tetapi terbagi-bagi ke dalam bagian-bagian kecil. Ada sekitar enam surat yang memuat kisah secara rinci dan lengkap antara lain surat Taha, al-A'raf, al-Qasas, al-Naml, al-Shu'ara' dan al-Kahfi. Mengalisis dari kisah Musa dalam surat al-Kahfi, khususnya QS. al-Kahfi ayat 70-82.

Kisah yang lebih sering menjadi kisah nubuwwat anak kecil, kali ini dicoba untuk dimaknai sebagai konsep dasar pendidikan andragogi perspektif pendidikan Islam. Maka dari itu, dibutuhkan analisis konten dengan menggunakan pendekatan naratif al-Quran terhadap kandungan cerita dalam al-Kahfi: 60-82 sebagai sumber data utama dan kisah Nabi MusaKhidr yang dijadikan objek kajian dalam penelitian ini.

Studi ini berusaha menyajikan bentuk naratif dialog antara Musa dan Khidr dalam QS.al-Kahfi ayat 60-82 sebagai pendahuluan. Sejarah dan prinsip teori andragogi juga menjadi kajian teori. Dari dua perspektif inilah, studi ini berusaha menyajikan formulasi nilai pendidikan Islam yang lebih khusus, mengambil dari kisah nabi Musa dan Khidr dengan prinsip teori andragogi dari Barat. Formulasi ini mengacu pada bagaimana nilai-nilai pendidikan dalam kisah nabi Musa dan Khidr menggambarkan prinsip pendidikan pendidikan orang dewasa perspektif pendidikan Islam. Sehingga teori andragogi perspektif pendidikan Islam memberikan celah pendidikan Islam untuk ikut berkontribusi terhadap dunia pendidikan pada umumnya.

\section{Narasi Dialog Musa dan Khidr}

Rangkaian kejadian (sekuen) cerita tentang perguruan Musa kepada Nabi Khidir menggunakan teknik pengaluran padat dengan berbagai peristiwa fungsional sebagai pembangunnya. Al-Quran memang tidak menyebutkan awal kisah pertemuan Musa dan Khidr. Namun, diceritakan oleh Nabi Muhammad saw. bahwasannya kisah ini diawali dengan pengakuan Nabi Musa sebagai orang yang paling dalam ilmunyaketika berkhutbah di depan Bani Isra'il. Lalu Allah mewahyukan bahwa ada seorang hamba yang lebih mengetahui di pertemuan dua lautan (Majma' al-Babrain). ${ }^{6}$ Musa pun diberitahu bahwa ia

${ }^{2}$ Choiruddin Hadhiri Sp, Klasifikasi Kandungan Al-Quran I, dalam M. Faisol, 2017, "Interpretasi Kisah Nabi Musa Perspektif Naratologi al-Quran.” Islamica: Jurnal Studi Keislaman, 11 (2), h. 365-392.

${ }^{3}$ Eksistensi cerita dalam al-Qur'ân diproyeksikan demi tujuan mulia terkait dengan risalah yang diemban oleh Nabi Muhammad dan sekaligus sebagai bukti kenabian (dala'il al-nubuwwah). M. Faisol, Ibid.

${ }^{4}$ Penyebutan yg lebih banyak ini pasti memiliki signifikansi bagi dakwah Nabi Muhammad, terlepas visi spiritual hingga eskatologis yaitu nilai etis yang hendak disampaikan kepada umat manusia. Mohammed Arkoun, Berbagai Pembacaan Quran, terj. Machasin, (Jakarta: INIS, 1997).

${ }^{5}$ M. Faisol, Ibid.

${ }^{6}$ M. Quraish Shihab, Tafsir Al-Misbab: Pesan, Kesan, dan Keserasian al-Quran, vol. 7, cet. ke-5, (Jakarta: Lentera Hati, 2012), h. 334. 
akan sampai di tempat yang dituju dengan membawa seekor ikan yang dibungkus daun kurma. Musa juga akan bertemu dengan hamba itu ketika ikan yang dibawanya hilang.

Dalam bagian ini, cerita dibuka dengan penggambaran cukup jauhnya jarak yang ditempuh oleh Musa dengan ditemani pembantunya untuk bertemu dengan seorang guru, disebutkan seorang hamba yang dianugerahi rahmat dan diajarkan suatu ilmu kepadanya? Secara implisit, pengantar awal cerita ini mengisyaratkan akan kegigihan Musa untuk berguru kepada Khidir.

Cerita perguruan diawali ketika Musa merasa lapar dan meminta pembantunya ${ }^{8}$ untuk memberikan bekal makanan yang dibawa. Sang pembantu memberitahu bahwa ikan sebagai bekal yang dibawanya, telah hilang saat mereka berdua berlindung di batu. Musa pun menegaskan bahwa tempat hilangnya ikan itulah tempat yang sedang dicari. ${ }^{9}$ Pada awalnya niat Musa untuk berguru ditolak oleh Khidir. Akan tetapi, berkat desakan dan kegigihan Musa akhirnya dia diterima dengan syarat Musa harus mampu bersabar selama berguru dengannya, tidak boleh bertanya sedikitpun. ${ }^{10}$

Perguruan antara keduanya berlanjut hingga mereka meneruskan perjalanan. Dalam perjalanan itu, keduanya dihadapkan pada tiga kejadian, yaitu: pertama, mereka menaiki sebuah perahu dan Khidir melobanginya, Musa merasa heran dan melanggar janjinya untuk tidak bertanya, Khidr pun memaafkan Musa; kedua, mereka mendapati seorang bocah dan Khidir malah membunuhnya, Musa pun melanggar janjinya untuk kedua kalinya dan Khidr mengingatkan untuk tidak mengulanginya kembali; ketiga, mendapati sebuah tembok (dinding) rumah yang hampir roboh dan Khidir menegakkannya, Musa yang tidak menerima perlakuan Khidr akhirnya memberi saran dan Khidr merasa kecewa lalu mengakhiri perguruan mereka karena Musa telah melanggar janjinya. Selama perjalanan itu, Musa pun gagal berguru karena tidak memenuhi janji untuk tidak bertanya. Akhirnya Nabi Khidir memutuskan untuk berpisah dengan Musa. Cerita pun ditutup dengan penjelasan Khidir kepada Musa tentang peristiwa yang telah diperbuat sebelumnya.Selanjutnya hamba Allah yang saleh itu menjelaskan tentang latar belakang tiga peristiwa yang telah mereka lalui bersama.

Khidr pun menjelaskan bahwa bahtera itu adalah kepunyaan orang-orang miskin yang digunakan bekerja di laut untuk mengais rezeki. Khidr memiliki tujuan merusakkan bahtera itu sehingga kapal itu dipandang tidak layak digunakan atau memiliki kulaitas rendah. ${ }^{11}$ Ia melakukannya karena di hadapan mereka ada seorang raja yang kejam yang selalu memerintah prajuritnya untuk merampas tiap-tiap bahtera yang masih berfungi baik. Sehingga dengan rusaknya perahu maka raja kejam itu tidak akan mengambil perahu milik orang miskin tersebut. ${ }^{12}$

Khidr mengatakan bahwa anak yang dibunuh memiliki kedua orangtua mukmin yang mantap keimanannya. Mereka menyebutkan bahwa khawatir jika anak itu hidup dan tumbuh dewasa maka akan membebani kedua orang tuanya dengan beban yang sangat berat. Akibat keberanian dan kekejaman anaknya menjadikan keduanya melakukan kedurhakaan dan kekufuran. Maka dengan membunuhnya, Khidr dengan niat di dalam dada dan Allah swt dengan kuasan-Nya menghendaki supaya Allah mengganti untuk mereka berdua dengan anak yang lebih baik darinya yakni dari anak yang dibunuh, Lebih baik dalam hal sikap

${ }^{7}$ Bayak ulama yang berpendapat bahwa hamba Allah yang dimaksud di sini yaitu Nabi Khidr. M. Quraish Shihab, Ibid, h. 340.

${ }^{8}$ Yaitu Yusya' bin Nun. M. Quraish Shihab, Ibid, h. 335.

9 Dinarasikan al-Quran dalam QS. al-Kahfi: 60-65. Ahmad Hatta, Tafsir Quran per Kata. Cet. ke-7. (Jakarta: Maghfiroh Pustaka, 2017), h. 300-301.

${ }^{10}$ Dinarasikan 1-Quran dalam QS. al-Kahfi: 66-70, Ahmad Hatta, Ibid, h. 301.

${ }^{11}$ M. Quraish Shihab, Ibid, h. 353.

12 QS. al-Kahfi: 79, Ahmad Hatta, Ibid, h. 302. 
keberagamaannya lebih mantap dalam hal kasih sayang dan baktinya kepada kedua orangtuanya. ${ }^{13}$

Peristiwa terakhir dijelaskan oleh Nabi Khidr dengan menyatakan bahwa dinding rumah yang ditegakkannya tanpa mengambil upah itu adalah milik dua orang anak yatim di negeri tersebut. Di bawahnya terdapat harta simpanan orangtua mereka untuk mereka berdua. Jika dinding itu roboh, kemungkinan besar harta simpanan akan ditemukan dan diambil oleh orang yang tidak berhak. Sedangkan ayah keduanya adalah orang yang salih dan niatnya menyimpan harta tersebut untuk kedua anaknya. Maka Allah menghendaki dipeliharanya harta itu agar mereka mencapai kedewasaan. Kemudian mengeluarkan dengan sungguh-sungguh simpanan kedua orangtuanya untuk mereka manfaatkan. Apa yang dilakukan Khidr semata-mata hanya sebagai rahmat terhadap kedua anak yatim itu dari Allah. Selanjutnya hamba Allah menegaskan bahwa apa yang dilakukan dari pembocoran perahu sampai penegakan tembok, itu bukan berdasar kemauannya sendiri. Tetapi semuanya adalah atas perintah Allah berkat ilmu yang diajarkan-Nya kepada Khidr. Ilmu itu didapatnya bukan karena usahanya tetapi semata-mata anugerah-Nya. ${ }^{14}$

Gambar 1: sketsa pembelajaran nabi Musa dan Khidr

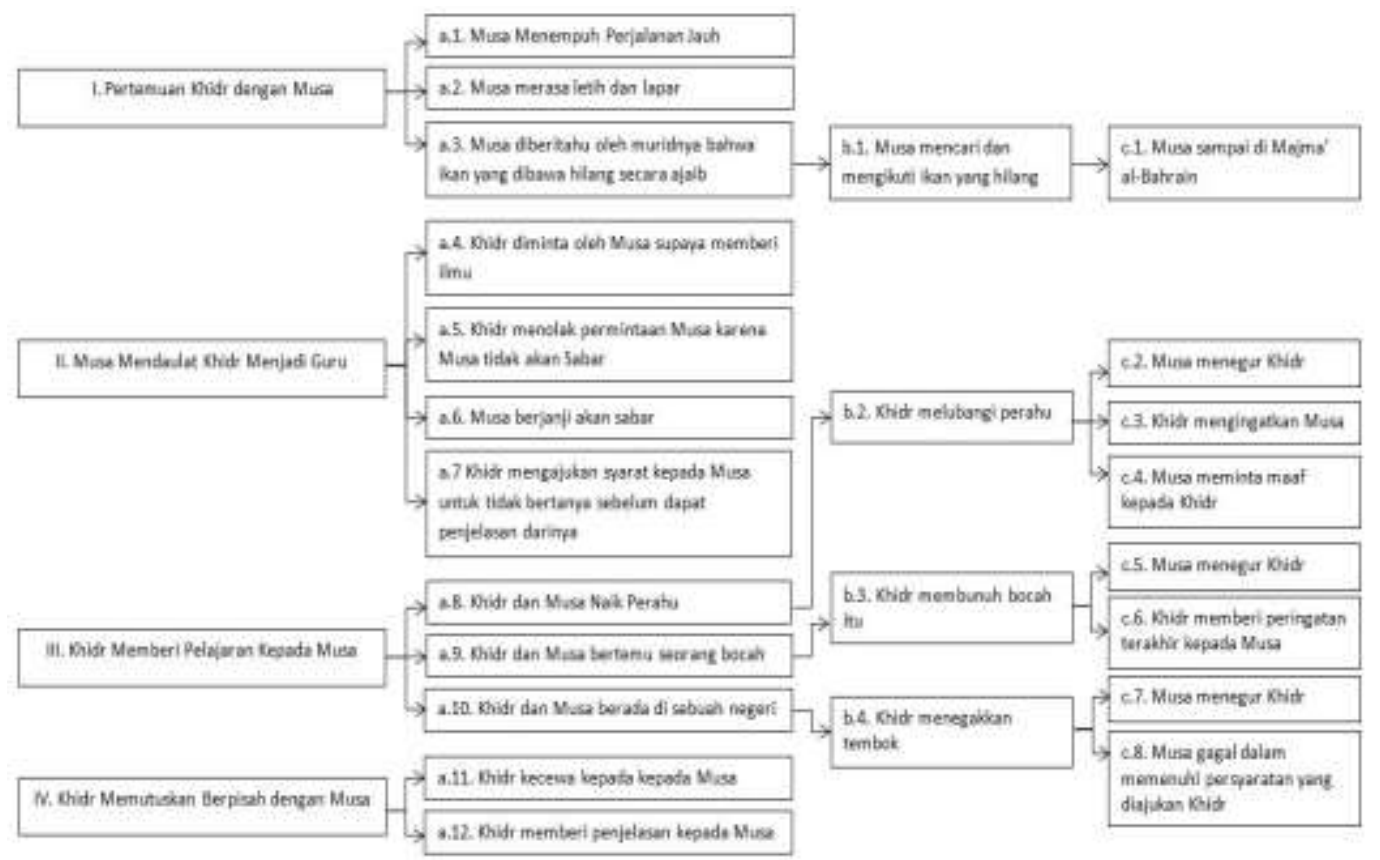

Dalam QS. al-Kahfi, cerita Nabi Musa dan Khidr dinarasikan dalam 23 ayat. Narasi Nabi Musa dan Khidr ini dapat dibagi menjadi empat rangkaian kejadian (sekuen). Di masing-masing rangkaian cerita diambil dari beberapa potongan ayat yaitu sekuen pertama ayat 60-65 mengisahkan perjalanan nabi Musa dengan ditemani pembantunya (Yusya bin Nun) untuk menemukan Khidr, sekuen kedua ayat 66-70 menceritakan pertemuan pertama antara musa dengan Khidr, sekuen ketiga ayat 71-77 menarasikan perjalanan musa dan Khidr, dan sekuen keempat ayat 78-82 menjelaskan perpisahan antara musa dengan Khidr.

\section{Nilai Pendidikan Islam dalam Dialog Nabi Musa dan Khidr}

Kisah Nabi Musa dan Khidr yang terkandung dalam QS. al-Kahfi menjadi salah satu kisah yang memuat nilai-nilai pendidikan yang sarat makna. Kisah Musa dalam al-Quran memiliki dimensi filosofis, historis, naratologis, dan futuristik yang memiliki visi jauh ke 
depan. ${ }^{15}$ Dapat diartikan bahwa nilai-nilai pendidikan dalam kisah Nabi Musa dan Khidr antara lain: ${ }^{16}$ (a) Nilai tawadhu'; Dikisahkan bahwa Musa merasa tidak ada orang yang pandai melebihi dirinya. Sehingga Allah memperingatkan bahwa masih ada hambaNya yang lebih pandai darinya. Sikap tawadhu' Musa yang bersedia belajar kepada Khidr sudah seharusnya terpatri dalam diri pembelajar. Karena dengan seseorang memiliki sikap tawadhu' akan mempermudahkan untuk menerima ilmu pengetahuan dari orang lain. (b) Rendah hati; Sikap rendah hati yang ditunjukkan Nabi Musa pada ayat di atas saat memohon kepada Khidr agar berkenan menjadi gurunya merupakan salah satu bentuk akhlak murid kepada guru. Selain itu, Nabi Musa juga tidak merasa malu memiliki kedudukan yang tinggi, meski dia tetap harus taat dan patuh pada perintah gurunya. (c) Nilai kesabaran dan tekad; Dalam sebuah ayat ${ }^{17}$ disebutkan bahwa Musa dengan tekad dan kesabaran akan melakukan perjalanan menemui orang yang lebih pintar dari dirinya. Secara implisit, cerita ini mengisyaratkan akan kegigihan Musa untuk berguru kepada Khidr. Selain Musa berjanji akan berbuat sabar dan tidak akan menentangnya, Khidr pun dengan sabar menerima permintaan Nabi Musa. Hal ini menunjukkan sikap sabar perlu tertanam dalam jiwa pembelajar, sebab kunci kesuksesan pembelajar sejatinya terletak pada tingkat kesabaran seseorang. ${ }^{18}$ (d) Nilai urgensitas fisik dan material sebagai kesiapan belajar; Dalam sebuah ayat ${ }^{19}$ yang dimaksudkan sebagai bekal ialah ikan. Walaupun dalam hal lain, bekal menuntut ilmu tidak hanya berupa makanan saja tapi juga dapat berupa materi, ilmu, dan kebutuhan lain yang sekiranya dibutuhkan dalam kurun menuntut ilmu. Seorang pencari ilmu pentingnya menyiapkan bekal sebelum memulai perjalanan pembelajarannya, selain tetap harus berawakkal kepada Allah.

Selain nilai di atas, nilai kependidikan secara umum yang tersirat dalam kisah Nabi Musa dan Khidr di antaranya yaitu: (1) Guru dan murid harus menyadari bahwa ilmu yang dimiliki keduanya sangat sedikit. Sehingga keinginan untuk selalu belajar akan selalu tumbuh dalam dirinya. Ditunjukan dengan perkataan Khidr ke Musa saat burung mematuk air laut. ${ }^{20}$ (2) Dalam proses belajar mengajar harus ditanamkan perasaan bahwa murid dibidang tertentu memiliki ilmu dan kemampuan, demikian juga guru memiliki ilmu dan kemampuan tertentu. $^{21}$ (3) QS. al-Kahfi ayat 70-82 mengandung beberapa komponen umum pendidikan meliputi: (a) Guru sebagai pengajar, Khidr sebagai objek yaitu sumber belajar nabi Musa. (b) Murid sebagai peserta didik, Musa sebagai subjek (Murid) orang yang belajar kepada Khidr.

${ }^{15}$ Salah satu unsur kisah yang digunakan dalam al-Quran adalah melalui personifikasi tokoh mengingat bahwa melalui cerita, jiwa dan pikiran seseorang akan mudah menerima pesan moral dan pendidikan. Naqrah At-Tuhami, Sikulujiyah al-Qishshah si al-Quran, (Tunis: al-Syirkah al-Tunisyah, 1971), h. 348.

${ }^{16}$ Lukman Arifin, "Nilai-nilai Edukasi dalam Kisah Musa-Khidr dalam al-Quran". Jurnal Dialektika. 8 (1), 2018, h. 28-39.

${ }^{17}$ Dan (ingatlah) ketika Musa berkata kepada muridnya: "Aku tidak akan berhenti (berjalan) sebelum sampai ke pertemuan dua buah lautan; atau aku akan berjalan sampai bertahun-tahun". (QS. al-Kahfi: 60).

${ }^{18} \mathrm{Grabbing}$ informations dapat dicapai dengan speed reading, tetapi untuk pemahaman mendalam yang diperlukan adalah deep reading. Amiruddin Siahaan, 2015, Pemikiran Pendidikan Imam Syafi'i: Peningkatan Kontribusi Manajemen Pendidikan Dalam Pengembangan Sumber Daya Manusia Berkualitas Untuk Membangun Masyarakat Ekonomi ASEAN: Proseding Manajemen Pendidikan Fakultas Ilmu Tarbiyah Dan Keguruan Universitas Islam Negeri Sumatra Utara, Perdana Publishing, h. 119-121.

${ }^{19}$ Maka tatkala mereka berjalan lebih jauh, berkatalah Musa kepada muridnya: "Bawalah ke mari makanan kita; sesungguhnya kita telah merasa letih karena perjalanan kita ini". (QS. al-Kahfi: 62)

${ }^{20}$ Selaras dengan sabda Rasulullah saw: "pertama kali yang dilakukan Musa as. adalah karena lupa". Kemudian ada seekor burung pipit hinggap di tepi perahu, lalu sekali patuk untuk minum ke laut. Melihat pemandangan itu, Khidr berkata kepada Musa as.: "ilmuku dan ilmumu dalam hubungannya dengan ilmu Allah, tidak lain hanyalah seperti air yang dipatuk dan diminum oleh burung itu dari air laut” Ibnu Katsir, Qishashul Anbiya' (Kisah Para Nabi), Diterj Moh Syamsi Hasan, (Surabaya: Amelia, 2008), h. 650.

${ }^{21}$ Dalam tafsir Ibnu Katsir menjelaskan bahwa sesungguhnya Khidr mempunyai ilmu yang diajarkan Allah kepadaku, yang tidak diajarkan kepada Musa. Sebaliknya, Musa pun mempunyai ilmu yang diajarkan Allah kepadanya, yang tidak diketahui Khidr. Ibnu Katsir, Ibid. h. 649. 
(c) Materi (Kurikulum) pengajaran, dalam hal ini ilmu-ilmu kasyfi ${ }^{22}$ Khidr. (d) Metode pengajaran dalam dialog Nabi Musa dan Khidr meliputi metode hiwar (dialog), ceramah, diskusi, demontrasi dan penemuan dan (e) Sarana pembelajaran yaitu Khidr membawa Musa ke tempat terbuka untuk melihat alam.

\section{Teori Pendidikan Andragogi}

Istilah andragogi seringkali dijumpai dalam proses pembelajaran orang dewasab baik di pendidikan formal maupun dalam proses pendidikan nonformal (pendidikan luar sekolah). Seringkali teori andragogi pada pendidikan formal digunakan pada tingkat menengah atas. Meskipun tidak harus didasarkan pada tigkat atau level pendidikan, posisi yang paling mendasar ialah kesiapan dan motivasi peserta didik untuk belajar.

Mengutip pengertian andragogi oleh UNESCO mendeskripsikan pendidikan orang dewasa sebagai suatu proses pendidikan yang terorganisir baik isi, metode dan tingkatannya, baik formal maupun nonformal. Adanya pendidikan ini tidak lain ialah membuat membuat orang yang dianggap dewasa oleh masyarakat dapat mengembangkan kemampuannya, memperkaya pengetahuannya, meningkatkan kualifikasi teknis maupun profesionalnya, dan mengakibatkan perubahan pada sikap dan perilakunya. ${ }^{23}$

Di sisi lain, teori andragogi juga dapat didefinisikan sebagai belajar orang dewasa yang merujuk pada kondisi peserta didik orang dewasa baik dilihat dari dimensi hukum, sosial, fisik (biologis), dan psikologisnya. Selain itu, tingkat dewasa juga dapat dilihat dari matangnya kondisi fisik, usia, kejiwaan, dan peran serta tugas dari status yang disandangnya.

Berikut ini diuraikan secara berurutan perkembangan yang lebih modern tentang sejarah perkembangan andragogi yang dikemukakan oleh berbagai ahli di antaranya yaitu:

\begin{tabular}{lcll}
\multicolumn{1}{c}{ Nama } & Tahun & \multicolumn{1}{c}{ Konsep dan Pemikiran yang dikembangkan } \\
\hline Alexander Kapp & 1833 & $\begin{array}{l}\text { Menjelaskan teori pendidikan yang dilahirkan ahli filsafat } \\
\text { Plato mengarah kepada pendidikan orang dewasa. }\end{array}$ \\
\hline Gernan Enchevort & 1833 & $\begin{array}{l}\text { Membahas asal mula pendidikan andragogi } \\
\text { Adam Smith }\end{array} 1919$ & $\begin{array}{l}\text { Pentingnya pendidikan dewasa dari karakter yang dimiliki } \\
\text { berbeda dengan tingkat anak-anak }\end{array}$ \\
\hline Eugen Rosenstock & 1921 & $\begin{array}{l}\text { Pendidikan orang dewasa dibutuhkan guru khusus, } \\
\text { metode khusus, dan filsafat khusus. }\end{array}$ \\
\hline Lawrence P. Jacks & 1929 & $\begin{array}{l}\text { Mengistilahkan pendidikan orang dewasa dengan } \\
\text { Continuing School yang berbasis pada pendapatan dan } \\
\text { kehidupan. }\end{array}$ \\
\hline Lyman Buson & 1936 & $\begin{array}{l}\text { Meninjau tujuan pendidikan orang dewasa dari segi sosial } \\
\text { untuk mencapai kesamaan program di setiap institusi } \\
\text { khusus orang dewasa. }\end{array}$ \\
\hline Harry Overstreet & 1949 & $\begin{array}{l}\text { Pentingnya menyusun konsep khusus pendidikan orang } \\
\text { dewasa }\end{array}$ \\
\hline Malcolm Knowles & 1950 & $\begin{array}{l}\text { Menjelaskan perbedaan pendidikan orang dewasa dan } \\
\text { pendidikan tradisional (Pedagogy) }\end{array}$ \\
\hline $\begin{array}{l}\text { M. Ogrizovic dan } \\
\text { Frans Poggeler }\end{array}$ & 1956 & $\begin{array}{l}\text { Memberi istilah andragogi sebagai konsep pendidikan } \\
\text { orang dewasa. }\end{array}$
\end{tabular}

${ }^{22} \mathrm{Ilmu}$ yang mengungkap sesuatu yang ghaib. Pakar-pakar tasawuf menamai ilmu yang berdasar mukasyafah (tersingkapnya sesuatumelalui cahaya kalbu) atau lebih dinamai ilmu ladunni. M.Quraish Shihab, Ibid, h. 340 .

${ }^{23}$ dalam persfektif rangkap perkembangan peribadi secara utuh dan partisipasi dalam pengembangan sosial, ekonomi, dan budaya yang seimbang. Sudjana, Pendidikan Luar Sekolah, Sejarah, Azas, (Bandung: Falah Production, 2000), h. 50. 
Dugan Sevicevic 1967 Mengistilahkan andragogi yang dipararelkan dengan pedagogi sehingga dikenal agogy

\begin{tabular}{lll}
\hline Malcolm Knowles & 1970 & $\begin{array}{l}\text { Memaparkan prinsip-prinsip pendidikan orang dewasa } \\
\text { sekaligus perbedaannya dengan pedagogi }\end{array}$ \\
\hline
\end{tabular}

Kidd JR dan 1973 Motivasi belajar orang dewasa ditinjau dari teori-teori dan

Malcolm Knowles praktek pedagogi

\begin{tabular}{lll}
\hline Malcolm Knowles & 1975 & kepribadian orang dewasa untuk menjadi manusia yang
\end{tabular} mandiri.

\begin{tabular}{lll}
\hline Knore AB & 1977 & Perkembangan perubahan karakter yang dimiliki orang
\end{tabular}
dewasa dan bentuk-bentuk pembelajarannya.

\begin{tabular}{|c|c|c|}
\hline Malcolm Knowles & 1980 & $\begin{array}{l}\text { Membedakan sistem metodologi dan ideologi dari } \\
\text { pendidikan pedagogi menuju pendidikan andragogi }\end{array}$ \\
\hline Patricia A Cross & 1981 & $\begin{array}{l}\text { Mengembangkan model pembelajaran orang dewasa sesuai } \\
\text { perkembangan demografis, sosial, dan teknologi. }\end{array}$ \\
\hline $\begin{array}{l}\text { Gordon G } \\
\text { Darkenwald dan } \\
\text { Sharan B Meriam }\end{array}$ & 1982 & $\begin{array}{l}\text { Dasar praktis pembelajaran orang dewasa didasarkan pada } \\
\text { karakteristik unik orang dewasa sebagai bentuk } \\
\text { pengembangan SDM. }\end{array}$ \\
\hline Malcolm Knowles & 1984 & $\begin{array}{l}\text { menyajikan gambaran tentang berbagai program teori } \\
\text { terapan yang didasarkan pada model Andragogy }\end{array}$ \\
\hline $\begin{array}{l}\text { Stephen } \\
\text { Brookfield }\end{array}$ & 1986 & $\begin{array}{l}\text { Gambaran fasilitasi pembelajaran dan mengidentifikasi } \\
\text { unsur-unsur praktek efektif yang menggambarkan konsep } \\
\text { fasilitasi pembelajaran orang dewasa }\end{array}$ \\
\hline
\end{tabular}

Orang dewasa mempunyai peran dan tugas tertentu di masyarakat yang tentunya dihadapkan pada problematika yang harus dipecahkan. Sehingga orang dewasa membutuhkan lifelong education untuk menyelesaikan problematika yang harus dihadapi. memaknai kesimpulan Rusman bahwa dinilai dari segi kemandirian dan kemampuan orang dewasa justru akan mempermudah orang dewasa dalam menyelesaikan pendidikannya. ${ }^{24}$

Menganalisis pendapat Malcolm Knowles ${ }^{25}$ tentang andragogi yang mengatakan bahwa teori andragogi paling sedikit didasarkan pada 4 asumsi dasar belajar orang dewasa, Pertama, konsep diri yaitu konsep pribadinya bergeser dari pribadi yang bergantung kepada orang lain (a dependent personality) menuju pribadi yang biasa mengarahkan diri sendiri (a selfdirecting human being). Seseorang dikatakan dewasa apabila dia mampu mengambil keputusan bagi dirinya, bertanggung jawab, dan sadar akan tugas dan perannya.

kedua, konsep pengalaman yaitu akumulasi dari pertumbuhan pengalamannya yang segudang menjadi sumber belajar yang kaya. Sehingga membentuk karakter masing-masing individu. Karena orang dewasa memiliki pengalaman lebih banyak sehingga pengalaman tersebut akan menjadi sumber belajar yang baik bagi setiap individu.

ketiga, konsep kesiapan belajar (readiness) untuk meningkatkan belajar orang dewasa yang diarahkan pada pengembangan tugas-tugas peranan sosialnya. Kesadaran seseorang terhadap kebutuhan belajar akan mendorong munculnya motivasi intrinsik untuk memenuhi kebutuhan hidupnya termasuk menyiapkan diri untuk belajar. Kesiapan belajar tidak ditentukan pada paksaan akademis maupun biologis tetapi lebih mengarah pada tuntutan perkembangan dan perubahan tugas serta peran sosialnya sebagai pekerja, orang tua, atau pemimpin organisasi. Tentunya hal ini akan mempengaruhi materi pembelajaran yang harus disesuaikan dengan kebutuhan belajarnya sesuai dengan peranan sosialnya.

keempat, perspektif waktu atau orientasi belajarnya berubah dari aplikasi pengetahuan yang sifatnya ditunda (postponed application of knowledge) menjadi aplikasi pengetahuan yang sifatnya mendesak (immediacy of application). Karena itu, orientasi belajarnya bukan lagi belajar

${ }^{24}$ Rusman, Model-model Pembelajaran: Mengambangkan Profesionalisme Guru, (Jakarta: Rajawali Pers, 2010).

${ }^{25}$ Malcolm, Ibid. 
berpusat pada mata pelajaran tetapi belajar berpusat pada masalah (problem solving). Sehingga makna belajar dalam andragogi bukanlah "persiapan untuk hidup" melainkan "sesuatu yang harus dilakukan agar bisa hidup". Hal ini juga selaras dengan konsep yang disebutkan UNESCO yaitu lifelong educatian.

\section{Analisis Kisah Nabi Musa dan Khidr dan Pendidikan Andragogi}

Berdasarkan pemaparan di atas, penulis memfokus kajian mengenai nilai pendidikan Islam yang terkandung dalam dialog edukatif nabi Musa dan Khidr dalam kerangka pendidikan andragogi yang dikaji dari empat asumsi dasar andragogi dan tiga kejadian yang yang dialami Musa dan Khidr pada QS. al-Kahfi ayat 70-82. Dengan berusaha menformulasikan nilai-nilai pendidikan Islam, studi ini berusaha menyajikan konsep pendidikan orang dewasa dalam perguruan Musa dan Khidr.

Meminjam pandangan tujuan pendidikan Muhammad Athiyyah al-Abrasyi maka pada tingkat pendidikan yang terjadi antara nabi Musa dan nabi Khidhr adalah tujuan individual. ${ }^{26}$ Tujuan individu dimaksud adalah bahwa sebagaimana tujuan pendidikan andragogi adalah untuk menyadarkan diri, maka ketika Allah menantang nabi Musa untuk mencari orang yang lebih pandai darinya karena memiliki ar-rusyd (kedewasaan) dan ketika nabi Khidhr dengan sabar mengajarkan kepada nabi Musa, sebenarnya nabi Khidhr ingin menyadarkan apa yang telah dilakukan oleh nabi Musa pada awal kelahiran sampai kenabian beliau.

Pada posisi nabi Khidhr sebagai seorang pendidik, maka ia memiliki fungsi sebagai pelatih ketrampilan dan perancang pengalaman belajar kreatif. Dalam konsep Islam, guru bisa disebut dengan al-Mursyid, karena dalam surat al-Kahfi disebutkan bahwa ar-Rusdu mengarah kepada kedewasaan nabi Khidhr, karakter ini belum dimiliki oleh nabi Musa sehingga diperintahkan Allah untuk belajar lagi. ${ }^{27}$ Dari sifat dan tingkah laku yang digambarkan oleh nabi Khidhr kepada nabi Musa, maka dapat dipaparkan bahwa nabi Khidhr sebagai seorang pendidik memiliki kompetensi jasmani dan rohani yang baik. Dalam konteks nabi Musa sebagai murid, maka hal yang menarik adalah adanya etika akademis antara guru dan murid, yaitu adanya kotrak belajar, etika bertanya, etika berdebat dan etika berdialog, yang kesemuanya mengarah kepada sebuah kedewasaan dalam proses interaksi antara keduanya.

Menilai analis kisah Musa Khidr dalam QS. al-Kahfi ayat 70-82 mengalami tiga kejadian besar dan empat asumsi andragogi dapat diformulasikan menjadi konsep pendidikan orang dewasa dalam perspektif pendidikan Islam. Konsep yang dijelaskan tersebut dapat dipaparkan sebagai berikut:

Pertama, Di antara citra diri yang dimiliki oleh nabi Musa berdasarkan ayat-ayat di atas dapat dibagi menjadi dua yaitu citra diri sebagai orang pandai yang sombong (negatif) dan citra diri sebagai orang yang memiliki sense of curious atau keinginan tahu akan sesuatu yang kuat (positif). Citra diri yang digambar Musa di atas, juga dapat digambarkan dalam kata nafs yang dimiliki dalam diri manusia. Setidaknya dalam setiap diri manusia ada tiga nafs, yaitu daya bernafsu (an-nafs al-babimiyah) sebagai daya terendah, daya berani (an-nafs as-sabu'iyyah) sebagai daya pertengahan, dan daya berpikir (an-nafs an-nathiqah) sebagai daya tertinggi. ${ }^{28}$ Namun, dalam kisah Musa dan Khidr disarikan dari nilai tertinggi dan terendah, yaitu daya berpikir sebagai citra diri positif dan daya bernafsu sebagai citra negatif. Jika dilihat dari tiga kejadian dalam dialog Musa dan Khidr, maka akan tergambar sebagai berikut: (a) Peristiwa

\footnotetext{
${ }^{26}$ berupa penyadaran terhadap individu akan kemampuan dirinya sebagai seorang individu. Muhammad Athiyyah al-Abrasyi, Dasar-dasar Pokok Pendidikan Islam. cet. ke-5, (Jakarta: Bulan Bintang, 1987).

${ }^{27}$ Muhammad Aqsho, Drajat, "Pendidikan Andragogi: Kajian Tafsir dalam Surat al-Kahfi ayat 70-82" Tesis. (Medan: IAIN Sumatera Utara, 2011).

${ }^{28}$ Arifin Yanuar, Pemikiran-pemikiran Emas Para Tokob Pendidikan Islam: Dari Klasike bingga Modern, (Yogyakarta: IRCiSoD, 2018).
} 
Khidr melubangi kapal memberikan gambaran citra positif yaitu Musa mau menunjukkan kelemahan dirinya. Citra negatif yang ditunjukkan Nabi Musa dalam peristiwa ini adalah dengan mudahnya Nabi Musa melanggar janjinya. (b) Pada kejadian pembunuhan anak, Nabi Musa menunjukkan citra positifnya yaitu mempunyai welas asih yang tinggi dan pribadi yang pantang menyerah dalam menuntut ilmu. Walaupun dalam hal ini, Nabi Musa sudah ditegur dua kali oleh gurunnya. Sedangkan citra negatifnya, Nabi Musa kurang bertanggung jawab atas kesempatan kedua yang diberikan gurunya. Karena pada kejadian kedua ini tergambarkan seolah-olah Nabi Musa sengaja menentang tindakan gurunya. (c) Pertolongan menegakkan dinding rumah anak yatim mengingatkan Nabi Musa akan tugas dan perannya sebagai Nabi untuk saling tolong menolong tanpa pamrih. Akan tetapi, Nabi Musa malah menyuruh gurunya untuk meminta imbalan atas bantuan yang diberikan gurunya. Padahal di sini, nabi Musa tidak menunjukkan sikap membantu gurunya.

Kedua, Dalam perjalanannya, nabi Musa sebagai seorang individu telah mengalami dan mengumpulkan berbagai pengalaman pahit-getirnya kehidupan pada zamannya, di mana hal ini menjadikan seorang Musa baik sebagai individu dan nabi menjadikan pengalamannya sebagai sumber belajar kaya. Dalam konteks tiga kejadian besar yang dialami Musa dan Khidr, konsep pengalaman ini dapat juga digambarkan dalam riblab yang menjadi salah satu metode pendidikan pemikiran Ibnu Khaldun. ${ }^{29}$ Rihlah tersebut tergambar dalam penjelasan tafsir Qurthubi berikut ini: (a) Kejadian ketika Khidhr merusak kapal sebenarnya Khidhr ingin menyadarkan bahwa nabi Musa ketika bayi pun pernah dibuang, padahal nabi Musa anak yang baik, tampan dan sempurna, tetapi Allah menyuruh ibunya membuangnya ke sungai Nil, hal ini sebenarnya isyarat sebagai salah satu bentuk perlindungan Allah terhadap kelahiran nabi Musa. Karena dikhawatirkan kelahirannya dikeahui oleh Fir'aun dan menyuruh pasukannya untuk membunuh seperti pada bayi laki-laki yang lain masa itu. ${ }^{30}$ (b) Ketika nabi Khidhr membunuh anak kecil, sebenarnya nabi Khidhr menyadarkan apa yang telah dilakukan oleh nabi Musa ketika membunuh seseorang dari bani Qibthi. ${ }^{31}$ (c) Ketika nabi Khidhr membetulkan rumah anak yatim yang akan hancur, sebenaranya nabi Musa sedang disarakan bahwa beliau pernah melakukan perbuatan yang sama yaitu menolong seorang wanita yang sedang mengambil air di sumur dan ternyata wanita tersebut menjadi istrinya. $^{32}$

Ketiga, Kesiapan belajar atau lebih dikenal sebagai isti'dad dalam pendidikan Islam adalah pengalaman dan perjalanan hidup nabi Musa yang semakin matang sesuai dengan berbagai tantangan dan hambatan. Maka ketika ada tantangan untuk mencari ilmu yang dimiliki oleh Khidhr, ketika ditantang Allah swt. Kesiapan waktu untuk belajar juga merupakan ciri tersendiri yang dilakukan oleh nabi Musa dengan mengajak sahabatnya untuk mencari orang yang lebih pintar dari dirinya. Jika kesiapan belajar tersebut dinyatakan dalam tiga kejadian yang dialami Musa, maka isti'dad yang dimaksud dalam pendidikan Islam juga dapat terbagi berikut ini: (a) Ketika peristiwa melubangi perahu yang lakukan oleh Khidr, dapat disebutkan bahwa sebelum Musa menerima kesanggupan atas syarat yang diberikan Khidr kepadanya, secara tidak langsung Musa telah membekali dirinya untuk selalu siap menerima perlakuan apapun, tekat yang kuat dan kepercayaan yang diberikan kepada

${ }^{29}$ Arifin Yanuar, Pemikiran-pemikiran Emas Para Tokob Pendidikan Islam: Dari Klasike bingga Modern, (Yogyakarta: IRCiSoD, 2018), h. 327.

${ }^{30}$ Kejadian ini dikisahkan dalam al-Quran: Dan Kami ilhamkan kepada ibu Musa; "Susuilah dia, dan apabila kamu khawatir terhadapnya maka jatuhkanlah dia ke sungai (Nil)" (QS.al-Qashas ayat 7).

${ }^{31}$ Pengalaman Nabi Musa ini dikisahkan dalam al-Quran yaitu "Maka orang yang dari golongannya meminta pertolongan kepadanya, untuk mengalahkan orang yang dari musuhnya lalu Musa meninjunya, dan matilah musuhnya itu. (QS.al-Qashas ayat 15).

${ }^{32}$ Peristiwa ini dinarasikan dalam Quran: Berkatalah dia (Syuaib): "Sesungguhnya aku bermaksud menikahkan kamu dengan salah seorang dari kedua anakku ini...” (QS.al-Qashas ayat 27). 
gurunya. ${ }^{33}$ Selain itu Musa juga membekali dirinya baik dari segi materi maupun non material. ${ }^{34}$ (b) Isti'dad Nabi Musa dalam proses pembunuhan anak menunjukkan bahwa nabi Musa harus memiliki ketabahan dan kesabaran dalam menghadapi perbuatan Khidr yang tak masuk akal. ${ }^{35}$ (c) Dalam peristiwa membangun dinding rumah anak yatim, Nabi Musa justru memberi saran kepada Khidr untuk meminta upah kepada pemilik rumah. Dari peristiwa ini, Nabi Musa sungguh telah menyiapkan keberanian dan tekat yang kuat untuk berdialog dengan gurunya walaupun waktunya tidak tepat. Bahkan Musa juga sanggup mengajukan negoisasi ulang dan siap menerima resiko lebih besar dari seblumnya. ${ }^{36}$

Keempat, Orientasi belajar nabi Musa berkenaan dengan upanya untuk mencari tantangan baru yaitu untuk membuktikan bahwa dirinya memiliki kemampuan yang lebih dibandingkan dengan orang lain padahal ketika ditelusuri secara mendalam ada orang yang lebih pandai darinya. Lebih dari itu, tindakan nabi Musa untuk belajar kepada Khidr ditinjau dari tujuan Pendidikan Islam menunjukkan cita-cita mulia menuju insan kamil (manusia sempurna). Lebih lanjutnya, insan kamil yang diharapkan dapat dipahami dari rincian berikut ini: (a) Argumen Khidr melubangi perahu mengandung arti bahwa seorang guru seharusnya berupaya mengajarkan kepada murid-murid mengenai bagaimana cara membantu orangorang lemah. Dengan kata lain seorang guru tidak hanya memperhatikan kognif anak saja tapi juga masa afektif dan psikomotorik peserta didik. Hal ini mencoba memberikan gambaran pada Nabi Musa bahwa apa terlihat dengan indrawi tidak selamanya menunjukkan kebenaran. Karena di sisi ini Nabi Musa dikenalkan pada ilmu ladunni ${ }^{37}$ yang dimiliki oleh Khidr. (b) Pembunuhan anak dapat diartikan secara majaz, yang bermakna seorang guru dituntut agar mampu memahami psikologi muridnya seraya membunuh karakter jelek yang terdapat dalam diri murid-muridnya. Dalam segi ini, Musa dapat belajar cara meredam emosinya dengan bersabar. (c) Pembangunan dinding secara tidak langsung menuntut sorang guru agar memperhatikan anak yatim piatu, sebab jika dibiarkan kelak akan menjadi beban sosial karena jauh dari kasih sayang. Kisah ini mengajak Nabi Musa untuk selalu mengayomi dan menyayangi kaum-kaum yang memiliki tingkat derajat lebih rendah dari dirinya.

Dari kasus di atas, secara tidak langsung memberi gambaran seorang guru seharusnya ikhlas mengajar dan dapat berbuat adil terhadap muridnya, apapun kedudukan sosialnya. Perkataan Khidr yang perlu dicatat adalah "dan ingatlah, aku tidak melakukannya menurut kemauanku sendiri". Pernyataan ini mencerminkan bahwa apa yang dilakukan Khidr adalah semata menjalankan perintah Allah. Walaupun secara lahiriyah terlihat absurd dan bertentangan dengan syariat, akan tetapi karena perintah Allah maka tetap dilaksanakan dan tentu ada hikmahnya.

Berdasarkan penjelasan di atas, formulasi konsep pendidikan orang dewasa perspektif pendidikan Islam dalam kisah nabi Musa dan Khidr dapat dipetakan sebagai berikut ini:

\footnotetext{
${ }^{33}$ Musa berkata kepada muridnya: "Aku tidak akan berhenti (berjalan) sebelum sampai ke pertemuan dua buah lautan; atau aku akan berjalan sampai bertahun-tahun" (QS. al-Kahfi: 60).

34"Bawalah ke mari makanan kita; sesungguhnya kita telah merasa letih karena perjalanan kita ini" (QS. al-Kahfi: 62).

${ }^{35}$ Musa berkata: "Janganlah kamu menghukum aku karena kelupaanku dan janganlah kamu membebani aku dengan sesuatu kesulitan dalam urusanku".

${ }^{36} \mathrm{Hal}$ tersebut dinyatakan langsung oleh nabi Musa dalam ayat berikut: Musa berkata: "Jika aku bertanya kepadamu tentang sesuatu sesudah (kali) ini, maka janganlah kamu memperbolehkan aku menyertaimu, sesungguhnya kamu sudah cukup memberikan uzur padaku" (QS. al-Kahfi: 76).

${ }^{37} \mathrm{Al}-\mathrm{Quran}$ telah mengisyaratkan dalam QS. al-Alaq: 4-5.
} 
Peta 1: Peta Pemiikiran Relasional (Analisis Kisah Musa dan Khidr - Pendidikan Andragogi)

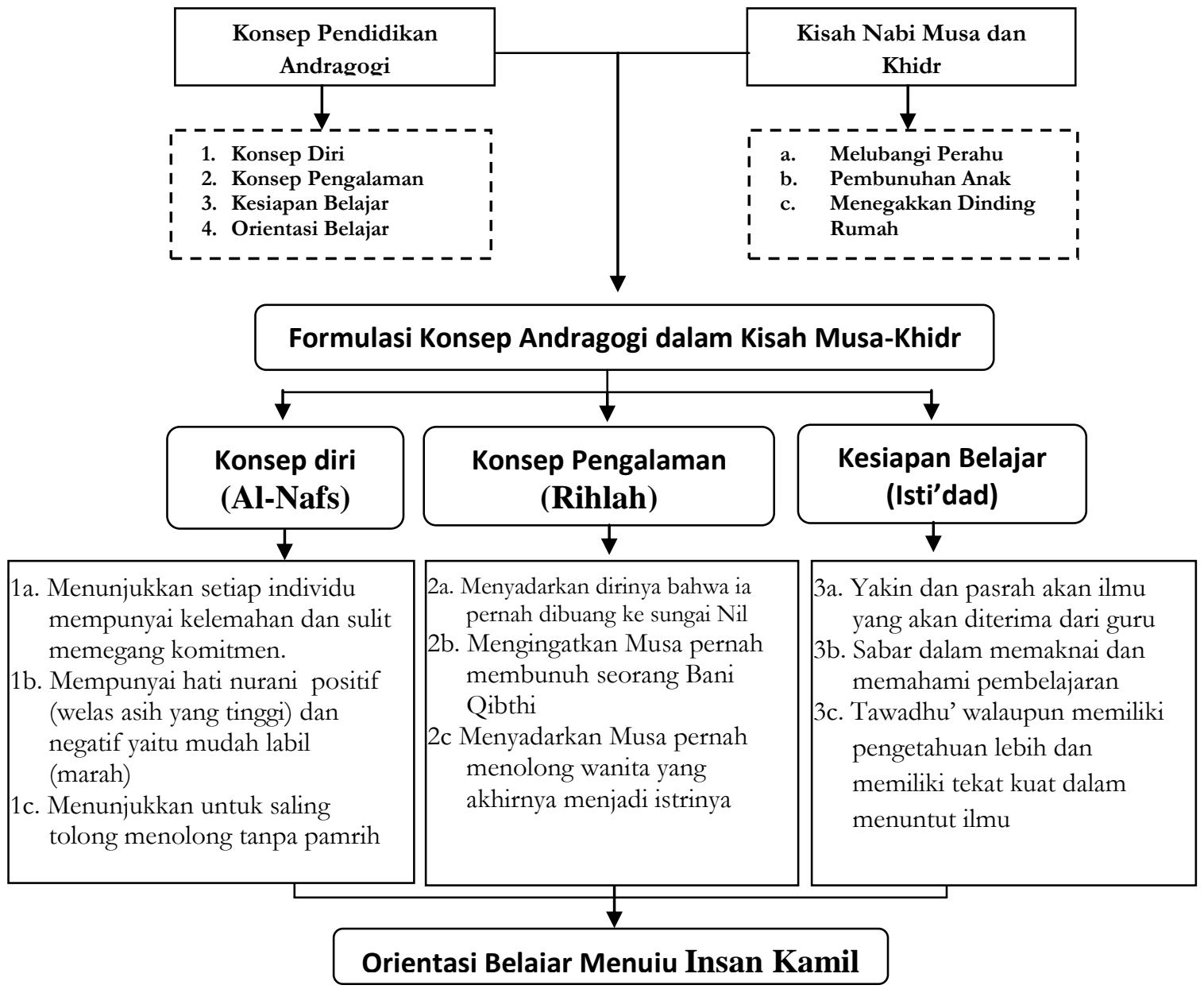

Gambar peta di atas, konsep pendidikan andragogi, yang memiliki empat asumsi dasar dan kisah nabi Musa dan Khidr, dalam tiga kejadian pembelajarannya, memiliki keterhubungan yang dapat diformulasikan menjadi pemikiran relasional andragogi perspektif pendidikan Islam. Dari hasil formulasi tersebut asumsi andragogi dalam kisah Musa dan Khidr memiliki tiga konsep yang lebih mirip dengan suatu metode pembelajaran, yaitu konsep diri (an-nafs), konsep pengalaman (riblab), dan kesiapan belajar (isti'dad). Ketiga konsep tersebut pada dasarnya memberikan gambaran pembelajaran atau hikamah hasil 
analisis kisah Musa-Khidr ialah untuk menjadi pribadi insan kamil, yaitu manusia sempurna dunia-akhirat.

\section{Simpulan}

Narasi kisah Musa memperlihatkan dimensi kemukjizatan naratologis (al-ifjâr, al-sardiy) alQur'ân. Kisah Musa dan Khidr mengandung nilai-nilai pendidikan Islam seperti akhlak antara murid dan guru, sikap tawadhu, rendah hati, kesabaran, dan tekat yang kuat dalam menuntut ilmu. Dilihat dari kondisi peserta didik, baik dari dimensi psikologi, sosial, fisik (biologis), hukum, dan tuntutan tugas dari statusnya sebagai Nabi, Musa dan Khidr memiliki kesesuaian dengan definisi pendidikan orang dewasa. Formulasi konsep antara keduanya, teori andragogi dan kisah Musa dan Khidr dapat dikelompokkan menjadi empat, yaitu pertama, al-nafs yaitu hasil telaah asumsi konsep diri dalam pendidikan Islam; kedua, riblah bermakna perjalanan yaitu konsep pengalaman yang didapatkan dari perjalanan seorang murid; ketiga, isti'dad bermakna persiapan sebagai bentuk analisis dari asumsi kesiapan belajar dalam pendidikan Islam; keempat, insan kamil sebagai bentuk orientasi belajar atau capaian dalam pendidikan Islam yaitu menuju hakikat manusia sempurna yang memiliki akal. Jika asumsi teori pendidikan andragogi ditarik ke dalam pendidikan Islam maka tiga asumsi yang lebih mirip dengan metode (al-nafs, rihlah, dan isti'dad) akan mengarah kepada pembentukan insan kamil.

\section{Daftar Pustaka}

Abu Abdullah Muhammad ibn Muhammad al-Ansary al-Qurthūbi, (1967). Jāmi al-Abkēm alQur'ān. Kairo: Dar al-Kitab al-Arabi li at-Tiba'ah wa an-Nasyr.

Achmadi, (1992). Islam sebagai Paradigma Ilmu Pendidikan. Yogyakarta: Aditya media.

Arifin, Lukman, (2018). Nilai-nilai Edukasi dalam Kisah Musa-Khidr dalam al-Quran. Jurnal Dialektika. 8 (1).

Arifin, Yanuar, (2018). Pemikiran-pemikiran Emas Para Tokoh Pendidikan Islam: Dari Klasik bingga Modern. Yogyakarta: IRCiSoD.

Arkoun, Mohammed, (1997). Berbagai Pembacaan Quran, terj. Machasin. Jakarta: INIS.

Basri. 2015. "Peran Pendidikan Luar Sekolah dalam pembelajaran Andragogi terhadap Pendidikan Sekolah" Jurnal Andragogi. 9 (2).

Choiruddin Hadhiri Sp, (2008), Klasifikasi Kandungan Al-Quran I

Drajat, Muhammad Aqsho. (2011). "Pendidikan Andragogi: Kajian Tafsir dalam Surat alKahfi ayat 70-82" Tesis. Medan: IAIN Sumatera Utara.

Ekoto, Cristian E., dan Prema, Gaikwad. (2015). The Impact of Andragogy on Learning Satisfaction of Graduate Students" American Journal of Educational Research. 3 (11).

Faisol, M. (2017). "Interpretasi Kisah Nabi Musa Perspektif Naratologi al-Quran." ISLAMICA: Jurnal Studi Keislaman. 11 (2).

Faisol, M. (2011). "Struktur Naratif Cerita Nabi Khidr dalam al-Quran" Adabiyyat. 10 (2).

Hatta, Ahmad. (2017). Tafsir Quran per Kata. Cet. ke-7. Jakarta: Maghfiroh Pustaka.

Katsir, Ibnu. (2008). Qishashul Anbiya' (Kisah Para Nabi). Diterjemahkan Moh Syamsi Hasan. Surabaya: Amelia.

Knowles, M. (1984). The Adult Learner: A Neglected Species (3rd Ed.). Houston: Gulf Publishing.

Knowles, Malcolm Shepherd, (1998). The Adult Learner: The Definite Classic in Adult Education and Human Resource Development. Houston: Gulf Publishing Company.

Muhaimin, (2009). Rekonstruksi Pendidikan Islam: Dari Paradigma Pengembangan, Manajemen Kelembagaan hingga Strategi Pembelajaran. Jakarta: Rajawali Pers.

Muhammad Athiyyah al-Abrasyi, (1987). Dasar-dasar Pokok Pendidikan Islam. cet. ke-5. Jakarta: Bulan Bintang. 
Naqrah, At-Tuhami, (1971). Sikulujizah al-Qishshah si al-Quran. Tunis: al-Syirkah al-Tunisyah. Qurthūbi, Abu Abdullah Muhammad ibn Muhammad al-Anshāry. Jāmi al-Ahkām al-Qur'ān. Kairo: Dār al-Kitāb al-Arabi li at-Tiba'āh wa an-Nasyr.

Ramayulis, (2015). Ilmu Pendidikan Islam. cet. ke-15. Jakarta: Kalam Mulia.

Rusman. (2010). Model-model Pembelajaran: Mengambangkan Profesionalisme Guru. Jakarta: Rajawali Pers.

Sandlin, Jennifer A. (2005). "Andragogy and Its Discontent: An Analysis of Andragogy from Three Critical Perspecrives" PAACE Journal of Livelong Learning. Shihab, M. Quraish. (1996). Wawasan Al-Qur'a. cet, ke-1. Bandung: Mizan.

Shihab, M. Quraish. (2012). Tafsir Al-Misbab: Pesan, Kesan, dan Keserasian al-Quran. Volume 7. Jakarta: Lentera Hati.

Shihab, M. Quraish. (2016). Wawasan Al-Qur'an. cet. I. Bandung: Mizan.

Siahaan, Amiruddin, (2015). Pemikiran Pendidikan Imam Syafi'i: Peningkatan Kontribusi Manajemen Pendidikan Dalam Pengembangan Sumber Daya Manusia Berkualitas Untuk Membangun Masyarakat Ekonomi ASEAN: Proseding Manajemen Pendidikan Fakultas Ilmu Tarbiyah Dan Keguruan Universitas Islam Negeri Sumatra Utara, Perdana Publishing.

Sudjana, D., (2000). Pendidikan Luar Sekolah, Sejarah, Aras. Bandung: Falah Production.

Tafsir, Ahmad, (2004). Ilmu Pendidikan dalam Perspektif Islam, cet. I. Bandung: Rosdakarya.

Taylor, Bryan., dan Michael, Kroth. (2009). "Andragogy's Transition Into The Future: MetaAnalysis of Andragogy and Its Search for a Measurable Instrument" Journal of Adult Education. 38 (1).

Umar Tirtarahardja \& La Sulo, (2000). Pengantar Pendidikan. Jakarta: Rineka. 